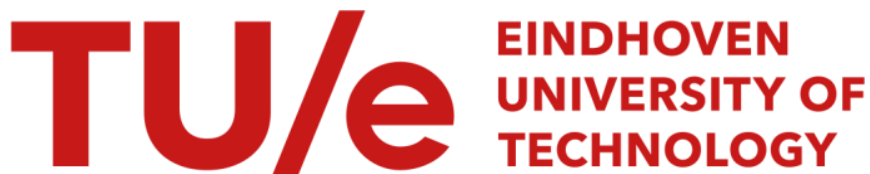

\section{The infinite horizon open-loop Nash LQ-game}

\section{Citation for published version (APA):}

Engwerda, J. C. (1996). The infinite horizon open-loop Nash LQ-game. (Katholieke Universiteit Brabant. Fac. Economische Wetenschappen : research memorandum; Vol. 741). Katholieke Universiteit Brabant.

Document status and date:

Published: 01/01/1996

\section{Document Version:}

Publisher's PDF, also known as Version of Record (includes final page, issue and volume numbers)

\section{Please check the document version of this publication:}

- A submitted manuscript is the version of the article upon submission and before peer-review. There can be important differences between the submitted version and the official published version of record. People interested in the research are advised to contact the author for the final version of the publication, or visit the $\mathrm{DOI}$ to the publisher's website.

- The final author version and the galley proof are versions of the publication after peer review.

- The final published version features the final layout of the paper including the volume, issue and page numbers.

Link to publication

\section{General rights}

Copyright and moral rights for the publications made accessible in the public portal are retained by the authors and/or other copyright owners and it is a condition of accessing publications that users recognise and abide by the legal requirements associated with these rights.

- Users may download and print one copy of any publication from the public portal for the purpose of private study or research.

- You may not further distribute the material or use it for any profit-making activity or commercial gain

- You may freely distribute the URL identifying the publication in the public portal.

If the publication is distributed under the terms of Article 25fa of the Dutch Copyright Act, indicated by the "Taverne" license above, please follow below link for the End User Agreement:

www.tue.nl/taverne

Take down policy

If you believe that this document breaches copyright please contact us at:

openaccess@tue.nl

providing details and we will investigate your claim. 
The Infinite Horizon

Open-Loop Nash

LQ-Game

Jacob C. Engwerda

FEW 741

Communicated by Prof.dr. J.M. Schumacher 


\title{
THE INFINITE HORIZON OPEN-LOOP NASH LQ-GAME
}

\author{
Jacob C. Engwerda \\ Tilburg University \\ Department of Econometrics \\ P.O. Box 90153 \\ 5000 LE Tilburg \\ The Netherlands \\ email: engwerda@kub.nl \\ December 10, 1996
}




\begin{abstract}
In this paper we consider the linear-quadratic differential game with an infinite planning horizon. We derive both necessary and sufficient conditions for existence of open-loop Nash equilibria for this garne. Furthermore we show how all equilibria can be easily obtained from the eigenspace structure of a Hamiltonian matrix that is associated with the game.
\end{abstract}

Keywords: Linear quadratic differential games, open-loop Nash equilibria, solvability conditions, Riccati equations 


\section{Introduction}

The last decade there has been an increasing interest to study several problems in economics using a dynamic game theoretical setting. In particular in the area of environmental economics and macro-economic policy coordination this is a very natural framework to model problems (see e.g. de Zeeuw et al. (1991), Mäler (1992), Kaitala et al. (1992) and Dockner et al. (1985), Tabellini (1986), Fershtman et al. (1987), Petit (1989), Levine et al. (1994), van Aarle et al. (1995), Douven et al (1995)). In, e.g., policy coordination problems usually two basic questions arise i.e., first, are policies coordinated and, second, which information do the participating parties have. Usually both these points are rather unclear and, therefore, strategies for different possible scenarios are calculated and compared with eachother. One of these scenarios is the so-called open-loop strategy. This scenario can be interpreted as that the parties simultaneously determine their strategy, next submit their strategies to some authority who then enforces these plans as binding commitments. So, this strategy is based on the assumption that the parties act non-cooperatively and that the only information they have on the model is its present state and the model structure. Obviously, since according this scenario the participating parties can not react to eachother's policies, its economic relevance is mostly rather limited. However, as a benchmark to see how much parties can gain by playing other strategies, it plays a fundamental role. Due to its analytic tractability the open-loop Nash equilibrium strategy is in particular very popular for problems where the underlying model can be described by a (set of) linear differential equation(s) and the individual objectives the parties are striving for can be approximated by functions which quadratically penalize deviations from some (equilibrium) targets. Under the assumption that the parties only have a finite-planning horizon, this problem was first modeled and solved in a mathematically rigorous way by Starr and Ho in (1969) (see also Lukes et al (1971), Eisele (1982) and Engwerda (1996) for extensions and more precise formulations).

In Abou-Kandil et al. (1993), Weeren (1995) and Engwerda (1996) also convergence of this equilibrium strategy was studied if the planning horizon expands. Like in the optimal linear quadratic regulator theory it turns out that under some conditions it can be shown that this stralegy converges. Furthermore, this converged solution is rather easy to calculate and much easier to implement than the finite planning horizon equilibrium solution.

So, the question arises whether this (converged) solution also solves the game if the parties consider an infinite-planning horizon. In Engwerda (1996) this problem was partly solved. That is, on the one hand a sufficient condition was given under which open-loop Nash equilibria exist and, on the other hand, for stable systems both a necessary and sufficient existence condition was derived. In this paper we will extend this approach. We will show that the condition derived in the above mentioned paper is also necessary and sufficient for the general case. We will conclude this paper by a discussion on the consequences of this result for numerical calculation of equilibrium solutions and by considering some special cases when (generically) a unique equilibrium exists.

The outline of the paper is as follows. In section two we start by stating the problem 
analysed in this paper and present some preliminary properties. Section three contains the basic result, whereas section four contains the concluding remarks.

\section{Preliminaries}

In this paper we consider the problem where two parties (henceforth called players) try to minimize their individual quadratic performance criterion. Each player controls a different set of inputs to a single system, described by a differential equation of arbitrary order. As already mentioned in the introduction we assume that both players have to formulate their strategy already at the moment the system starts to evolve and this strategy can not be changed once the system runs. So, the players have to minimize their performance criterion based on the information that they only know the differential equation and its initial state. We are looking now for combinations of pairs of strategies of both players which are secure against any attempt by one player to unilaterally alter his strategy. That is, for those pairs of strategies which are such that if one player deviates from his strategy he will only lose. In the literature on dynamic games this problem is well-known as the open-loop Nash non-zero-sum linear quadratic differential game (see e.g. Starr and Ho (1969), Simaan and Cruz (1973), Başar and Olsder (1982) or Abou-Kandil and Bertrand (1986)). Formally the system we consider is as follows:

$$
\dot{x}=A x+B_{1} u_{1}+B_{2} u_{2}, x(0)=x_{0},
$$

where $x$ is the n-dimensional state of the system, $u_{i}$ is an $m_{i}$-dimensional (control) vector player $i$ can manipulate, $x_{0}$ is the initial state of the system, $A, B_{1}$, and $B_{2}$ are constant matrices of appropriate dimensions, and $\dot{x}$ denotes the time derivative of $x$.

The performance criterium player $i=1,2$ aims to minimize is:

$$
\lim _{t_{j} \rightarrow \infty} J_{i}\left(u_{1}, u_{2}\right)
$$

where

$$
J_{1}\left(u_{1}, u_{2}\right):=\frac{1}{2} \int_{0}^{t_{f}}\left\{x(t)^{T} Q_{1} x(t)+u_{1}(t)^{T} R_{11} u_{1}(t)\right\} d t
$$

and

$$
J_{2}\left(u_{1}, u_{2}\right):=\frac{1}{2} \int_{0}^{t_{f}}\left\{x(t)^{T} Q_{2} x(t)+u_{2}(t)^{T} R_{22} u_{2}(t)\right\} d t
$$

in which matrix $R_{i i}$ is positive definite, $Q_{i}$ is semi-positive definite and additionally is positive definite w.r.t. the controllability subspace $\left\langle A, B_{i}\right\rangle, i=1,2$.

Note that usually in literature each player's performance criterium also includes a cross term, penalizing the control efforts of the other player. Since, however, this cross term does not play a role in the analysis of open-loop Nash equilibria, we dropped this term here (see any of the references quoted above).

The set of admissible control functions we consider, is given by $U:=$

$$
\left\{\left(\begin{array}{l}
u_{1}(t) \\
u_{2}(t)
\end{array}\right), t \in[0, \infty) \mid \lim _{t_{f} \rightarrow \infty} J_{i}\left(u_{1}, u_{2}\right)<\infty, i=1,2 .\right\}
$$


Note that $U$ depends on the initial state of the system. For simplicity of notation we omit, however, this dependency. Furthermore, it is clear that $u_{i}(.) \in L^{2}$, the set of square integrable functions, but that $U$ is not a linear subspace of $L^{2}$. First, since the zero-function will in general not belong to $U$ and, second, in general with $v, w \in \dot{U}$, $v+w \notin U$. However, $U$ does satisfy the following important property:

\section{Lemma 1:}

Assume that both $v$ and $v+w$ are an element of $U$. Then for any real $\epsilon$ also $v+\epsilon w \in U$.

\section{Proof:}

First we introduce some notation.

Let $x_{u}$ denote the state trajectory obtained by using the control function $u$, that is, $x_{u}(t):=e^{A t} x_{0}+\int_{0}^{t} e^{A(t-\tau)}\left(B_{1} B_{2}\right) u(\tau) d \tau$.

Since by assumption both $v$ and $v+w$ belong to $U, x_{v}(t)$ and $x_{v+w}(t)$ converge to zero if $t \rightarrow \infty$. So, $x_{v}(t)-x_{v+w}(t)=\int_{0}^{t} e^{A(t-\tau)}\left(B_{1} B_{2}\right) w(\tau) d \tau \rightarrow 0$, if $t \rightarrow \infty$. Moreover, since both $x_{v}$ and $x_{v+v}$ are square integrable, also the righthandside of the above equation is square integrable. Now, consider $x_{v+\varepsilon w}(t)$. Elementary calculation shows that $x_{v+c w}(t)=x_{v+w}(t)-(1-\epsilon) \int_{0}^{t} e^{A(t-\tau)}\left(B_{1} B_{2}\right) w(\tau) d \tau$. So, using the above result, it is clear that $x_{v+c w}(t)$ is square integrable. Moreover, since both $v$ and $v+w$ are square integrable it follows that $w$ has to be square integrable too. From this follows then immediately that also $v+\epsilon w$ is square integrable.

Combining both results gives then that $\lim _{i_{j} \rightarrow \infty} J_{i}(v+\epsilon w)<\infty, i=1,2$. Which implies that $v+\epsilon w \in U$.

Next, we introduce the set of coupled algebraic asymmetric Riccati-type equations associated with this problem:

$$
\begin{aligned}
& 0=-A^{T} K_{1}-K_{1} A-Q_{1}+K_{1} S_{1} K_{1}+K_{1} S_{2} K_{2} ; \\
& 0=-A^{T} K_{2}-K_{2} A-Q_{2}+K_{2} S_{2} K_{2}+K_{2} S_{1} K_{1},
\end{aligned}
$$

where $S_{i}=B_{i} R_{i i}^{-1} B_{i}^{T}, i=1,2$.

We will see in the next section that the solutions $K_{1}, K_{2}$ to this set of equations, that satisfy an additional stability property, play a similar role like the stabilizing solution of the algebraic Riccati equation in the standard $L Q$ regulator problem.

\section{The equilibrium strategies}

The basic result of this paper is summarized in the next theorem:

\section{Theorem 2:}

The two-player linear quadratic differential game (1) has for every initial state an openloop Nash equilibrium $\left(\begin{array}{l}u_{1} \\ u_{2}\end{array}\right)$ if and only if there exist $K_{1}$ and $K_{2}$ that are solutions 
of the algebraic Riccati equations (ARE) satisfying the additional constraint that the eigenvalues of $A_{c l}:=A-S_{1} K_{1}-S_{2} K_{2}$ are all situated in the left half complex plane. In that case, the strategy

$$
u_{i}(t)=-R_{i i}^{-1} B_{i}^{T} K_{i} x(t), i=1,2
$$

is an open-loop Nash equilibrium strategy.

Moreover, the costs obtained by using this strategy for the players are

$$
\int_{0}^{\infty}\left\{\left(e^{A_{c l t}} x_{0}\right)^{T}\left(Q_{i}+K_{i}^{T} S_{i} K_{i}\right) e^{A_{c l t} t} x_{0} d t, i=1,2 .\right.
$$

Proof:

$" \Leftarrow "$ This part was proved by Engwerda (1996), theorem 12 .

$" \Rightarrow "$ To prove this part we use the variational approach (see e.g. Friedman (1971), Lukes and Russell (1971) and Engwerda (1996)).

Suppose that $\bar{u}_{1}, \bar{u}_{2}$ are a Nash solution. That is,

$$
J_{1}\left(u_{1}, \bar{u}_{2}\right) \geq J_{1}\left(\bar{u}_{1}, \bar{u}_{2}\right) \text { and } J_{2}\left(\bar{u}_{1}, u_{2}\right) \geq J_{2}\left(\bar{u}_{1}, \bar{u}_{2}\right) .
$$

Then, for any control function $\left(\begin{array}{c}w \\ 0\end{array}\right)$ such that $\left(\begin{array}{c}\bar{u}_{1}+w \\ \bar{u}_{2}\end{array}\right) \in U$ we have, according lemma 1 , that for any real number $\epsilon$

$$
J_{1}(\epsilon):=J_{1}\left(\bar{u}_{1}+\epsilon w, \bar{u}_{2}\right) \geq J_{1}\left(\bar{u}_{1}, \bar{u}_{2}\right) .
$$

Let $x_{\bar{u}}(t)$ and $x_{\bar{u}+\epsilon w}(t)$ be the solutions to (1) corresponding to the controls $\left(\begin{array}{l}\bar{u}_{1} \\ \bar{u}_{2}\end{array}\right)$ and $\left(\begin{array}{c}\bar{u}_{1}+\epsilon w \\ \bar{u}_{2}\end{array}\right)$, respectively. Then it is easily verified that (see also proof of lemma 1 )

$$
x_{\bar{u}+\epsilon w}(t)=x_{\bar{u}}(t)+\epsilon g(t),
$$

where $g(t):=\int_{0}^{t} e^{A(t-s)} B_{1} w(s) d s$ is a square integrable function.

So, $J_{1}(\epsilon)$ can be rewritten as:

$$
\frac{1}{2} \int_{0}^{\infty} f(t, \epsilon) d t
$$

where

$$
\begin{gathered}
f(t, \epsilon):=\left(x_{\bar{u}}(t)+\epsilon g(t)\right)^{T} Q_{1}\left(x_{\bar{u}}(t)+\epsilon g(t)\right)+ \\
\left(\bar{u}_{1}(t)+\epsilon w(t)\right)^{T} R_{11}\left(\bar{u}_{1}(t)+\epsilon w(t)\right) .
\end{gathered}
$$

Note that $f(t, \epsilon)$ is differentiable w.r.t. $\epsilon$ for every $t \in(0, \infty)$. Simple calculations show that

$$
\begin{gathered}
\frac{\partial f}{\partial \epsilon}=2 \epsilon\left(g^{T}(t) Q_{1} g(t)+w^{T}(t) R_{11} w(t)\right)+ \\
2\left(g^{T}(t) Q_{1} x_{\tilde{u}}(t)+w^{T}(t) R_{11} \bar{u}_{1}(t)\right)
\end{gathered}
$$


Using the facts that $g(t), w(t)$ and $\bar{u}_{1}(t)$ are square integrable, it is obvious now that $\frac{\partial f}{\partial t}$ is integrable for, e.g., all $\epsilon \in[-1,1]$. Using standard arguments we lave then that $J_{1}(\epsilon)$ is differentiable on $(-1,1)$ and that

$$
\begin{gathered}
\frac{d J_{1}(\epsilon)}{d \epsilon}=\int_{0}^{\infty}\left\{c\left(g^{T}(t) Q_{1} g(t)+w^{T}(t) R_{11} w(t)\right)+\right. \\
\left.\left(g^{T}(t) Q_{1} x_{\bar{u}}(t)+w^{T}(t) R_{11} \bar{u}_{1}(t)\right)\right\} d t
\end{gathered}
$$

From (5) we get

$$
\left.\frac{d J_{1}(\epsilon)}{d \epsilon}\right|_{\epsilon=0}=0
$$

So, we get:

$$
\int_{0}^{\infty}\left\{g^{T}(t) Q_{1} x_{\bar{u}}(t)+w^{T}(t) R_{11} \bar{u}_{1}(t)\right\} d t=0 .
$$

Substitution of the expression for $g(t)$ into this equation and then interchanging the order of integration yields:

$$
\begin{gathered}
\int_{0}^{\infty}\left\{\int_{s}^{\infty}\left(e^{A(t-s)} B_{1} w(s)\right)^{T} Q_{1} x_{\bar{u}}(t) d t\right\} d s+ \\
\int_{0}^{\infty} w^{T}(t) R_{11} \bar{u}_{1}(t) d t=0 .
\end{gathered}
$$

Which can be restated as:

$$
\begin{gathered}
\int_{0}^{\infty}\left\{w^{T}(t) B_{1}^{T} e^{-A^{T} t} \int_{t}^{\infty} e^{A^{T_{s}}{ }} Q_{1} x_{\tilde{u}}(s) d s\right\} d t+ \\
\int_{0}^{\infty} w^{T}(t) R_{11} \bar{u}_{1}(t) d t=0 .
\end{gathered}
$$

Now, choose in the above expression consecutively $w(t):=\operatorname{sgn}\left[e_{i}^{T}\left(B_{1}^{T} \int_{t}^{\infty} e^{A^{T}(s-t)} Q_{1}\right.\right.$ $\left.\left.x_{\bar{u}}(s) d s+R_{11} \bar{u}_{1}(t)\right)\right] e^{-\lambda t} e_{i}, \mathrm{i}=1, . ., \mathrm{n}$, where $\lambda$ is an arbitrary real number larger than the spectral radius of matrix $A$ and $e_{i}$ is the $i$-th standard basis vector in $\mathbb{R}^{n}$. Then it is clear that for every choice of $w(t), \bar{u}_{1}+w(t) \in U$. Consequently it follows that

$$
\bar{u}_{1}(t)=-R_{11}^{-1} B_{1}^{T} \int_{t}^{\infty} e^{A^{T}(s-t)} Q_{1} x_{\bar{u}}(s) d s .
$$

Similarly, it can be shown that $\tilde{u}_{2}(t)$ necessarily satisfies:

$$
\bar{u}_{2}(t)=-R_{22}^{-1} B_{2}^{T} \int_{t}^{\infty} e^{A^{T}(s-t)} Q_{2} x_{\bar{u}}(s) d s
$$

Next, we introduce the vector $v:=\left(\begin{array}{lll}v_{1}^{T} & v_{2}^{T} & v_{3}^{T}\end{array}\right)^{T}$ as follows: $v_{1}(t):=x_{\bar{u}}(t), v_{2}(t):=$ $\int_{t}^{\infty} e^{A^{T}(s-t)} Q_{1} x_{\tilde{u}}(s) d s$ and $v_{3}(t):=\int_{t}^{\infty} e^{A^{T}(s-t)} Q_{2} x_{\hat{u}}(s) d s$. Then $\bar{u}_{1}=-R_{11}^{-1} B_{1}^{T} v_{2}(t)$ and $\bar{u}_{2}=-R_{22}^{-1} B_{2}^{T} v_{3}(t)$. Moreover, it is easily verified by differentiation of $v_{2}(t)$ and $v_{3}(t)$, that $v(t)$ satisfies

$$
\dot{v}(t)=-\left(\begin{array}{ccc}
-A & S_{1} & S_{2} \\
Q_{1} & A^{T} & 0 \\
Q_{2} & 0 & A^{T}
\end{array}\right) v(t), \text { with } v_{1}(0)=x_{0} .
$$


Since by assumption for arbitrary $x_{0}, v(t)$ converges to zero, it follows that there exist $K_{1}, K_{2}$ and a stable matrix $\Lambda$ such that $-\left(\begin{array}{ccc}-A & S_{1} & S_{2} \\ Q_{1} & A^{T} & 0 \\ Q_{2} & 0 & A^{T}\end{array}\right)\left(\begin{array}{c}I \\ K_{1} \\ K_{2}\end{array}\right)=\left(\begin{array}{c}I \\ K_{1} \\ K_{2}\end{array}\right) \Lambda$. Writing out these equations yields then the advertised result.

\section{Remark:}

Parts of the above proof can be substituted by using the results of Haurie et al. (1984, lemma 5.1). This requires, however, the introduction of the concept of weak overtaking optimality. In this framework it is not required that the state or the performance criterium converge (see Halkin (1974)). Since we like to stay in the framework of bounded performance criteria, we choose to give an elementary selfcontained proof of the theorem.

In the above theorem the costs for the individual players are expressed as an integral. In fact, analogously to the optimal LQ regulator theory, we have that the costs can be obtained indirectly by solving the following associated Lyapunov equations ${ }^{1}$

$$
A_{c l}^{T} M_{i}+M_{i} A_{c l}+Q_{i}+K_{i}^{T} S_{i} K_{i}=0,
$$

where $A_{c l}:=A-S_{1} K_{1}-S_{2} K_{2}, \mathrm{i}=1,2$.

Note that if all eigenvalues of $A_{c l}$ are in the left half complex plane and $Q_{i}+K_{i}^{T} S_{i} K_{i} \geq 0$, this equation has a unique positive semi-definite solution $M_{i}$. The equilibrium costs can then also be obtained as

\section{Proposition 3:}

Assume that $K_{1}, K_{2}$ solve (ARE) and satisfy the stabilization property mentioned in theorem 2. Let $M_{i}$ be the unique positive semi-definite solution of the above Lyapunov equation (11): Then,

$$
J_{i}\left(\bar{u}_{1}, \bar{u}_{2}\right)=x_{0}^{T} M_{i} x_{0}, i=1,2 .
$$

\section{Proof:}

Let $M_{i} \geq 0$ be the unique solution of (11). Then, using the notation $x(t):=e^{A_{c l t} t} x_{0}$, we have

$$
\begin{aligned}
J_{i}\left(\bar{u}_{1}, \bar{u}_{2}\right) & =\int_{0}^{\infty} x(t)^{T}\left(Q_{i}+K_{i}^{T} S_{i} K_{i}\right) x(t) d t \\
& =-\int_{0}^{\infty} x(t)^{T}\left(A_{c l}^{T} M_{i}+M_{i} A_{c l}\right) x(t) d t \\
& =-\int_{0}^{\infty} \frac{d}{d t}\left[x(t)^{T} M_{i} x(t)\right] d t \\
& =x_{0}^{T} M_{i} x_{0}-\lim _{t \rightarrow \infty} x(t)^{T} M_{i} x(t) \\
& =x_{0}^{T} M_{i} x_{0}
\end{aligned}
$$

\footnotetext{
"I like to thank Arie Weeren for pointing out this to me
} 
which proves the claim.

\section{The solutions for the algebraic Riccati equation}

In the previous section we saw that we can find all equilibrium solutions by determining all solutions $K_{1}, K_{2}$ of the set of algebraic Riccati equations (ARE), which satisfy the additional property that all eigenvalues of the corresponding matrix $A-S_{1} K_{1}-S_{2} K_{2}$ lie in the left half complex plane.

MacFarlane (1963) and Potter (1966) independently discovered that there exists a relationship between the stabilizing solution of the algebraic Riccati equation and the eigenvectors of a related Hamiltonian matrix in linear quadratic regulator problems. Abou-Kandil et al. (1993) already pointed out the existence of a similar relationship for our problem. One of their results was that if the planning horizon $t_{f}$ in (1) tends to infinity, under some technical conditions, the solution of the finite planning horizon problem converges to a solution which requires the calculation of a solution $K_{1}, K_{2}$ of (ARE) which can be calculated from the eigenspaces of the matrix

$$
M:=\left(\begin{array}{ccc}
-A & S_{1} & S_{2} \\
Q_{1} & A^{T} & 0 \\
Q_{2} & 0 & A^{T}
\end{array}\right)
$$

In Engwerda et al. (1995) this relationship between solutions of (ARE) and eigenspaces of matrix $M$ was elaborated. Using the notation $\mathcal{M}^{\text {inv }}$ for the set of all $M$-invariant subspaces, it was shown that all solutions for the set of algebraic Riccati equations can be calculated from the following subset of $M$-invariant subspaces:

$$
\mathcal{K}^{\text {pos }}:=\left\{\mathcal{K} \in \mathcal{M}^{i n v} \mid \mathcal{I} \oplus \operatorname{Im}\left(\begin{array}{cc}
0 & 0 \\
I & 0 \\
0 & I
\end{array}\right)=\mathbb{R}^{3 n}\right\} .
$$

Note that elements in this set $\mathcal{K}^{\text {pos }}$ can be calculated using the set of matrices

$$
K^{\text {pos }}:=\left\{K \in \mathbb{R}^{3 n \times n} \mid \operatorname{ImK} \oplus \operatorname{Im}\left(\begin{array}{ll}
0 & 0 \\
1 & 0 \\
0 & 1
\end{array}\right)=\mathbb{R}^{3 n}\right\}
$$

The following result was proved:

Proposition 4:

(ARE) has a real solution $\left(K_{1}, K_{2}\right)$ if and only if $K_{1}=Y X^{-1}$ and $K_{2}=Z X^{-1}$ for some $\mathcal{K}=: \operatorname{Im}\left(\begin{array}{c}X \\ Y \\ Z\end{array}\right) \in \mathcal{K}^{\text {pos }}$.

Moreover, if the control functions $u_{i}^{*}(t)=-R_{i i}^{-1} B_{i}^{T} K_{i} \Phi(t) x_{0}$ are used to control the system (1), the spectrum of the closed-loop matrix $A-S_{1} K_{1}-S_{2} K_{2}$ coincides with 
$\sigma\left(-\left.M\right|_{K}\right)$

From this result we first of all observe that every element of $\mathcal{K}^{\text {pos }}$ defines exactly one solution of (ARE). Furthermore, this set contains only a finite number of elements if and only if the geometric multiplicities of all eigenvalues of $M$ is one (see e.g. Lancaster and Tismenetsky (1985)). So, in that case we immediately conclude that (ARE) will have at most a finite number of solutions. Furthermore, we see that

Corollary 5:

(ARE) will have a set of solutions $\left(K_{1}, K_{2}\right)$ stabilizing the closed-loop system matrix $A-S_{1} K_{1}-S_{2} K_{2}$ if and only if there exists an $M$ invariant subspace $\mathcal{K}$ in $\mathcal{K}^{\text {pos }}$ such that Re $\lambda>0$ for all $\lambda \in \sigma\left(\left.M\right|_{K}\right)$.

So, the study of the equilibria of our LQ game boils down to the study of all $M$ invariant subspaces $\mathcal{K}$ in $\mathcal{K}^{\text {pos }}$ for which $\operatorname{Re} \lambda>0$ for all $\lambda \in \sigma\left(\left.M\right|_{\mathcal{K}}\right.$.

The next example illustrates that in general there may be more than one equilibrium:

Example 6:

In Engwerda et al. (1995) the following example was considered:

$A=\left(\begin{array}{cccc}0 & -1 & 0 & -1 \\ 0 & 1 & -1 & 0 \\ 0 & 0 & 1 & -1 \\ -2 & 0 & 0 & 1\end{array}\right), B_{1}=I_{4}, Q_{1}=\operatorname{diag}(3.5,2,4,5), Q_{2}=\operatorname{diag}(1.5,6,3,1)$, $R_{11}=I_{4}$, and $R_{22}=2 I_{4}$.

By considering the eigenvalues and corresponding eigenspaces of matrix $M$, it was shown that (ARE) has 7 solutions $K_{1}, K_{2}$ satisfying the stabilization property. So, according to theorem 2, for this choice of matrices, the infinite planning horizon game has 7 open-loop Nash equilibria.

\section{Concluding remarks}

In this paper we considered the existence of open-loop Nash equilibrium solutions in the two-player infinite-planning horizon linear quadratic game. We derived both necessary and sufficient conditions for existence of such equilibria. Furthermore we showed how these equilibria can be calculated from the invariant subspaces of the Hamiltonian matrix associated with this game $M=\left(\begin{array}{ccc}-A & S_{1} & S_{2} \\ Q_{1} & A^{T} & 0 \\ Q_{2} & 0 & A^{T}\end{array}\right)$. It turns out that the eigenvalues of the closed-loop system, if the open-loop control strategies are implemented in (1), can be obtained from the eigenvalues of this matrix.

As was illustrated in an example, in general the game will have more than one equilibrium. An important open problem remains the study of the eigenstructure of this matrix 
$M$.

One property, which was already noted in Engwerda (1996), is that if a discounting factor is included in the performance function that is large enough, matrix $M$ will have n stable eigenvalues. So, in that case there exists at most one equilibrium. Since generically the corresponding eigenvectors will be such that they together form an element of $\mathcal{K}^{\text {pos }}$, we get generically a unique equilibrium in the discounted case. Moreover, combining the results on scalar systems from Engwerda (1996) and the results of theorem 2, we have that for scalar systems there exists always a unique equilibrium.

Finally we note that the obtained results can be straightforwardly generalized to the $\mathrm{N}$ player game.

\section{References}

Aarle B. van, Bovenberg L. and Raith M., 1995, Monetary and fiscal policy interaction and government debt stabilization, Journal of Economics 62, no.2, pp.111-140.

Abou-Kandil H. and Bertrand P., 1986, Analytic solution for a class of linear quadratic open-loop Nash games, International Journal of Control, vol.43 no.3, pp.997-1002.

Abou-Kandil H., Freiling G. and Jank G., 1993, Necessary and sufficient conditions for constant solutions of coupled Riccati equations in Nash games; Systems\&Control Letters 21, pp.295-306.

Başar T. and Olsder G.J., 1982, Dynamic Noncooperative Game Theory, Academic Press London.

Dockner, Feichtinger G. and Jørgensen S., 1985, Tracktable classes of nonzero-sum openloop Nash differential games, Journal of Optimization Theory and Applications 45, no.2, pp.179-197.

Douven R.C. and Engwerda J.C., 1995, Is there room for convergence in the E.C.?, European Journal of Political Economy 11, pp.113-130.

Eisele T., 1982, Nonexistence and nonuniqueness of open-loop equilibria in linearquadratic differential games, Journal of Optimization Theory and Applications 37, no.4, pp.443-468.

Engwerda J.C., 1996, On the open-loop Nash equilibrium in LQ-games, Research Memorandum FEW 726, Tilburg University The Netherlands.

Engwerda J.C. and Weeren A.J.T.M, 1995, On the solutions of the algebraic Riccati equation corresponding to open-loop Nash equilibria in LQ-games, Proceedings of the third European Control Conference, eds. A. Isidori et al., pp.2615-2619. 
Fershtman C. and Kamien I., 1987, Dynamic duopolistic competition with sticky prices, Econometrica 55, no.5, pp.1151-1164

Friedman A., 1971, Differential Games, John Wiley \& Sons, New York.

Kaitala V., Pohjola M. and Tahvonen O., 1992, Transboundary air polution and soil acidification: a dynamic analysis of an acid rain game between Finland and the USSR, Environmental and Resource Economics 2, no.2, pp.161-181.

Lancaster P. and Tismenetsky M., 1985, The Theory of Matrices, Academic Press, London.

Levine P. and Brociner A., 1994, Fiscal policy coordination and EMU: a dynamic game approach, Journal of Economic Dynamics and Control 18, pp.699-729.

Lukes D.L. and Russell D.L., 1971, Linear-quadratic games, Journal of Mathematical Analysis and Applications 33, pp.96-123.

MacFarlane A.G.J., 1963, An eigenvector solution of the optimal linear regulator, J. Electron.Control 14, pp.643-654.

Halkin H., 1974, Necessary conditions for optimal control problems with infinite horizons, Econometrica 42, no.2, pp.267-272.

Haurie A. and Leitmann G., 1984, On the global asymptotic stability of equilibrium solutions for open-loop differential games, Large Scale Systems 6, pp.107-122

Mäler K.-G., 1992, Critical loads and international environmental cooperation, in: R. Pethig, ed., Conflicts and cooperation in managing environmental resources, Springer Verlag.

Petit M.L., 1989, Fiscal and monetary policy co-ordination: a differential game approach, J. of Applied Econometrics vol.4, pp.161-179.

Potter J.E., 1966, Matrix quadratic solutions, SIAM J. Appl. Math. 14, pp.496-501.

Simaan M. and Cruz J.B., Jr., 1973, On the solution of the open-loop Nash Riccati equations in linear quadratic differential games, International Journal of Control 18, no.1, pp.57-63.

Starr A.W. and Ho Y.C., 1969, Nonzero-sum differential games, Journal of Optimization Theory and Applications. 3, pp.184-206. 
Tabellini G., 1986, Money, debt and deficits in a dynamic game, Journal of Economic Dynamics and Control 10, pp.427-442.

Weeren A.J.T.M., 1995, Coordination in Hierarchical Control, PhD. Thesis Tilburg University, The Netherlands, ISBN 90-5668-006-4.

de Zeeuw A.J. and van der Ploeg F., 1991, Difference games and policy evaluation: a conceptual framework, Oxford Economic Papers 43, no.4, pp.612-636. 


\section{IN 1995 REEDS VERSCHENEN}

\section{Paul Smit}

The Approximation of an Eigenvector by Ritzvectors

Communicated by Prof.dr. M.H.C. Paardekooper

685 Harry Webers

The generalized circular model

Communicated by Prof.dr. A.J.J. Talman

686 Laurence A.G.M. van Lent

Pressure and Politics in Financial Accounting Regulation

Communicated by Prof.drs. G.G.M. Bak RA

687 B. de Rooij en G.J. van der Pijl

A contingency approach to Quality System Implementation

Communicated by Prof.dr.ir. C.A.Th. Takkenberg

688 Edwin R. van Dam en Willem H. Haemers

Graphs with constant $\mu$ and $\bar{\mu}$

Communicated by Prof.dr. S.H. Tijs

689 G. Facchini, F. van Megen, P. Borm and S. Tijs

Congestion models and weighted Bayesian potential games

Communicated by Prof.dr. A.J.J. Talman

690 Jos Grazell en Chris Veld

Alternatieve Perspectieven in de Theorie van de Ondernemingsfinanciering

Cornmunicated by Prof.dr. P.W. Moerland

691 Gert Hegge en Rezaul Kabir

Een nadere analyse van de relaties tussen aandelenrendementen en winsten, dividenden en cash-flows

Communicated by Prof.dr. P.W. Moerland

692 P. Jean-Jacques Herings

On the Representation of Admissible Rationing Schemes by Rationing Functions

Communicated by Prof.dr. A.J.J. Talman

693 P. Jean-Jacques Herings

Rigidity of Prices, the Generic Case?

Communicated by Prof.dr. A.J.J. Talman

694 Laurence A.G.M. van Lent, Rob C.W. Eken

Aansprakelijkheid: een teken van kwaliteit

Communicated by Prof.drs. G.G.M. Bak RA

695 Edwin R. van Dam, Willem H. Haemers

A characterization of distance-regular graphs with diameter three

Communicated by Prof.dr. M.H.C. Paardekooper 
696 Paul Smit

Generating Identical Ritz Values

Communicated by Prof.dr. M.H.C. Paardekooper

697 Antoon van den Elzen

An adjustment process for the standard Arrow/Debreu model with production

Communicated by Prof.dr. A.J.J. Talman

698 B. Kamp

Study regarding the structural discount of the price of Elsevier stock compared to the price of Reed stock

Communicated by Drs. P.J.W. Duffhues

699 Edwin R. van Dam

Bounds on separated pairs of subgraphs, eigenvalues and related polynomials

Communicated by Dr.ir. W.H. Haemers

700 Jelmer Boersma en Chris Veld

Het gebruik van financiele derivaten door grote Nederlandse ondernemingen

Communicated by Prof.dr. P.W. Moerland

701 Ad H.J.J. Kolnaar en Pieter J.F.G. Meulendijks

Zijn Cobbenhagen's ideeën opnieuw aktueel?

Communicated by Prof.dr. Th. van de Klundert

702 C.L.J.P. van Raalte en H.M. Webers

Spatial competition with intermediated matching

Communicated by Prof.dr. A.J.J. Talman

703 Herbert Hamers en Marco Slikker

The PEGS-rule for probabilistic sequencing situations

Communicated by Prof.dr. S. Tijs

704 Nick van der Lijn

Measuring well-being with social indicators, $\mathrm{HDI}^{\mathrm{S}}, \mathrm{POLI}$, and $\mathrm{BWI}$ for 133 countries for $1975,1980,1985,1988$ en 1992

Communicated by Prof.dr. J. James

705 Nick van der Lijn

Well-being, democracy, and the economic system: an empirical analysis

Communicated by Prof.dr. J. James

706 Jack P.C. Kleijnen

Sensitivity Analysis and Related Analyses: a Survey of Statistical Techniques

Communicated by Dr.Ing. W.J.H. van Groenendaal

707 Aldo de Moor

The Development of a Research Network Information System Specification Method Communicated by Prof.dr. R.A. Meersman

708 J.J.A. Moors, M.H. Schuld and A.C.A. Mathijssen 
A new method for assessing judgmental distributions

Communicated by Prof.dr. B.B. van der Genugten

709 Laurence van Lent

Onderzoek op het gebied van de externe verslaggeving

Communicated by Prof.drs. G.G.M. Bak

710 Josien van Cappelle-Konijnenberg

Restructuring, firm performance and control mechanisms

Communicated by Drs. P.J.W. Duffhues

711 B.B. van der Genugten

Blackjack in Holland Casino's: basic, optimal and winning strategies

Communicated by Dr. A.M.B. De Waegenaere

712 Prof.dr. F.W. Vlotman

Het vragen naar Toegevoegde Waarde

Communicated by Prof.dr.mr. P.M. v.d. Zanden RA 


\section{IN 1996 REEDS VERSCHENEN}

713 Jeroen Suijs en Peter Borm

Cooperative games with stochastic payoffs: deterministic equivalents

Communicated by Prof.dr. A.J.J. Talman

714 Herbert Hamers

Generalized Sequencing Games

Communicated by Prof.dr. S.H. Tijs

715 Ursula Glunk en Celeste P.M. Wilderom

Organizational Effectiveness = Corporate Performance?

Why and How Two Research Traditions Need to be Merged

Communicated by Prof.dr. S.W. Douma

716 R.B. Bapat en Stef Tijs

Incidence Matrix Games

Communicated by Prof.dr. A.J.J. Talman

717 J.J.A. Moors, R. Smeets en F.W.M. Boekema

Sampling with probabilities proportional to the variable of interest

Communicated by Prof.dr. B.B. van der Genugten .

718 Harry Webers

The Location Model with Reservation Prices

Communicated by Prof.dr. A.J.J. Talman

719 Harry Webers

On the Existence of Unique Equilibria in Location Models

Communicated by Prof.dr. A.J.J. Talman

720 Henk Norde en Stef Tijs

Determinateness of Strategic Games with a Potential

Communicated by Prof.dr. A.J.J. Talman

721 Peter Borm and Ben van der Genugten

On a measure of skill for games with chance elements

Communicated by Prof.dr. E.E.C. van Damme

722 Drs. C.J.C. Ermans RA and Drs. G.W. Hop RA

Financial Disclosure: A Closer Look

Communicated by Prof.drs. G.G.M. Bak RA

723 Edwin R. van Dam \& Edward Spence

Small regular graphs with four eigenvalues

Communicated by Dr.ir. W.H. Haemers

724 Paul Smit

Inexact Iterations for the Approximation of Eigenvalues and Eigenvectors

Communicated by Prof.dr. M.H.C. Paardekooper 
725 Tammo H.A. Bijmolt, Michel Wedel

A Monte Carlo Evaluation of Maximum Likelihood Multidimensional Scaling Methods

Communicated by Prof.dr. R. Pieters

726 J.C. Engwerda

On the open-loop Nash equilibrium in LQ-games

Communicated by Prof.dr. J.M. Schumacher

727 Jacob C. Engwerda en Rudy C. Douven

A game-theoretic rationale for EMU

Communicated by Prof.dr. J.E.J. Plasmans

728 Willem H. Haemers

Disconnected vertex sets and equidistant code pairs

Communicated by Prof.dr. S. Tijs

729 Dr. J.Ch. Caanen

De toekomst van de reserve assurantie eigen risico

Communicated by Prof.dr. A.C. Rijkers

730 Laurence van Lent

The Economics of an Audit Firm: The Case of KPMG in the Netherlands

Communicated by Prof.drs. G.G.M. Bak RA

731 Richard P.M. Builtiens, Niels G. Noorderhaven

The Influence of National Culture on Strategic Decision Making:

A Case Study of the Philippines

732 S. Tijs, F. Patrone, G. Pieri, A. Torre

On consistent solutions for strategic games

Communicated by Prof.dr. A.J.J. Talman

733 A.J.W. van de Gevel

From Strategic Trade Policy to Strategic Alliances in the Global Semiconductor Industry

Communicated by Prof.dr. A.B.T.M. van Schaik

734 M. Voorneveld, $H$. Norde

A Characterization of Ordinal Potential Games

Communicated by Prof.dr. S. Tijs

735 J.C. de Vos, B.B. van der Genugten

Fitting a stochastic model for Golden-Ten

Communicated by Dr.ir. A.A.F. van de Ven

736 Gert Nieuwenhuis

Ergodicity Conditions and Cesaro Limit Results for Marked Point Processes

Communicated by Prof.dr. B.B. van der Genugten 
737 P.J.F.G. Meulendijks, D.B.J. Schouten Dynamiek, Analyse en Politiek

Communicated by Prof.dr. A.H.J.J. Kolnaar

738 Antoon van den Elzen

Constructive application of the linear tracing procedure to polymatrix games

Communicated by Prof.dr. A.J.J. Talman

739 René van den Brink

Skewness of the Wage Distribution in a Firm and the Substitutability of Labor Inputs

Communicated by Prof.dr. P.H.M. Ruys

740 Sharon Schalk

General Equilibrium Model with a Convex Cone as the Set of Commodity Bundles

Communicated by Prof.dr. A.J.J. Talman 